\title{
Análisis crítico del discurso en la apertura de los diálogos de paz en Colombia (2012)*
}

LUZMILA ÁLVAREZ ROMERO*** luzmila200@hotmail.com

LUZ ENITH SUÁREZ SUÁREZ**** colpa.enith@hotmail.com

Forma de citar este artículo: Álvarez Romero, L., \& Suárez Suárez, L.E. (2016). Análisis crítico del discurso en la apertura delos diálogos de paz en Colombia (2012). Cuadernos de Lingüística Hispánica, (28), 69-89. doi: http://dx.doi.org/10.19053/0121053X.4909

* Artículo de investigación científica.

** Licenciada en Educación Básica con Énfasis en Humanidades Lengua castellana, Magíster en Linguística. Docente colegio Parroquial San Luis Gonzaga de Barbosa (Santander).

*** Licenciada en Educación Básica con Énfasis en Humanidades Lengua Castellana, Magíster en Linguística. Docente del Colegio Integrado Lucas Caballero de Suaita (Santander). 


\title{
Resumen
}

Este artículo presenta los resultados del análisis crítico del discurso de los delegados del Gobierno Nacional y de las FARC, en la instalación de la mesa de los diálogos de paz en Oslo (Noruega, 2012), con el propósito de reconocer los recursos lingüísticos y estrategias discursivas empleadas por los interlocutores para determinar significaciones implícitas en el universo simbólico creado por los actores sociales hegemónicos. La metodología se apoyó en dos fases: una exploratoria descriptiva y otra analítica. En la primera se seleccionó el corpus y se exploró mediante el programa informático NVivo 10. En la segunda, se analizaron los recursos lingüísticos que coadyuvarían en la construcción de las estrategias discursivas presentes y se interpretaron. Los resultados muestran el uso recurrente de las metáforas para conceptualizar la paz, la economía, las FARC, el Gobierno, Colombia, entre otros; y de cuantificadores para construir estrategias de legitimación de las acciones violentas de las FARC.

Palabras clave: análisis crítico del discurso, estrategias, recursos, lenguaje.

\section{Critical Discourse Analysis in the Opening of the Colombian Peace Talks (2012)}

\begin{abstract}
This article presents the results of the critical discourse analysis applied to national government delegates and the FARC, during the installment of the negotiation table of peace dialogues in Oslo (Norway, 2012), with the purpose of recognizing the linguistic resources and discursive strategies employed by the speakers, in order to determine the implicit significance in the symbolic universe created by these hegemonic social actors. The methodology was divided into two phases: a descriptive and explorative phase and an analytical phase. In the first one, a corpus was selected and explored using the NVivo 10 software. In the second phase, the linguistic resources that contributed to the building of discursive strategies were analyzed and interpreted. The results prove the recurring use of metaphors to conceptualize peace, economy, the FARC, the government, Colombia, among others; as well as the use of quantifiers in order to build legitimation strategies for the violent actions of the FARC.
\end{abstract}

Key words: Critical discouse analysis, strategies, resources, language. 


\section{Analyse critique du discours dans l'ouverture des dialoguesde paix en Colombie (2012)}

\section{Résumé}

Cet article présent les résultats de l'analyse critique du discours des délégués du Gouvernement National et des FARC, dans l'installation de la table des dialogues de paix à Oslo (Norvège, 2012), ayant l'intention de reconnaître les ressources linguistiques et des stratégies discursives employés par les interlocuteurs pour déterminer des significations implicites dans l'univers symbolique créé par les acteurs sociaux hégémoniques. La méthodologie s'est appuyée sur deux phases: l'une, exploratoire descriptive et l'autre analytique. Dans la première, on a sélectionné le corpus et on a exploré, grâce au programme informatique NVivo 10. Dans la deuxième, on a analysé les ressources linguistiques qui contribuent à la construction des stratégies discursives présentes, et ensuite on les a interprétées. Les résultats montrent, l'utilisation récurrente des métaphores pour conceptualiser la paix, l'économie, les FARC, le Gouvernement, la Colombie, entre autres; et aussi de quantificateurs pour construire des stratégies de légitimation des actions violentes des FARC.

Mots clés: analyse critique du discours, stratégies, ressources, langage.

\section{Análise crítica do discurso na abertura dos diálogos de paz na Colômbia (2012)}

\section{Resumo}

Este artigo apresenta os resultados da análise crítica do discurso dos delegados do Governo Nacional e das FARC, na instalação da mesa dos diálogos de paz em Oslo (Noruega, 2012), com o propósito de reconhecer os recursos linguísticos e as estratégias discursivas empregados pelos interlocutores para determinar significações implícitas no universo simbólico criado pelos atores sociais hegemônicos. A metodologia se apoiou em duas fases: uma exploratória descritiva e outra analítica. Na primeira se selecionou o corpus e se explorou mediante o programa informático NVivo 10. Na segunda, se analisaram os recursos linguísticos que coadjuvariam na construção das estratégias discursivas presentes e se interpretaram. Os resultados mostram o uso recorrente das metáforas para conceituar a paz, a economia, as FARC, o Governo, a Colômbia, entre outros; e de quantificadores para construir estratégias de legitimação das ações violentas das FARC.

Palavras chave: análise crítica do discurso, estratégias, recursos, linguagem. 


\section{Introducción}

Esta investigación tuvo como objetivo principal inferir las estrategias discursivas y los recursos linguísticos presentes en los discursos de los delegados del Gobierno Nacional y de las Fuerzas Armadas de Colombia (FARC), en la instalación de la mesa de los diálogos de paz en Oslo (Noruega, 2012), para dar cuenta de las formas como opera el lenguaje, no solo como forma de comunicación, sino como producto de la interacción permanente de los individuos dentro de la sociedad.

El Análisis Crítico del Discurso (ACD) permite comprender de una mejor manera el uso de la lengua en los contextos sociales, y facilita la caracterización de formas de dominación que se expresan a través de los discursos. Según Van Dijk (1993), analizar el discurso social implica estudiar las relaciones entre las estructuras del discurso y las estructuras de poder. De esta manera, es posible evidenciar las diversas estructuras lingüísticas empleadas para representar poder, para ejercer y reproducir dominación y para reconocer el conjunto de estrategias que construyen ocultamiento o muestran las desigualdades en las relaciones sociales.

Se seleccionó para el análisis el tema del proceso de paz, ya que Colombia es un país que por años ha soportado la crisis de un conflicto social armado, debido a la conocida guerra con las guerrillas en la que han participado organizaciones subversivas como las FARC. Con la idea de establecer ciertos acuerdos entre las partes, en varias ocasiones se han iniciado procesos en búsqueda de la paz, pero todos han sido intentos fallidos.

Para el análisis discursivo, se toman las formas de proceder de Pardo Abril (2007) en lo que se refiere a la configuración de tejidos de relaciones, palabras y conceptos estructurados con base en la reiteración y asociación estadísticas de unidades analíticas y su significación mediante la exploración directa de cada uno de los discursos, lo cual se evidenciará en las gráficas de frecuencias y asociaciones. Se cita a Van Dijk (1990) con las indicaciones pertinentes para la tematización de los discursos, luego se procede a la identificación de unidades conceptuales que posibilitan la concreción de unidades linguísticas que dan cuenta de un fenómeno o realidad específica. Además, se toma la propuesta de Isabella y Norman Faircluogh (2012) como nuevo enfoque para el análisis político; ellos recomiendan, para este caso, centrar la atención en la argumentación, 
puesto que la finalidad de dichas intervenciones está diseñada para persuadir y convencer a un grupo sobre una determinada ruta de acciones.

Las estrategias discursivas se sustentan en la teoría de Méndez (2000), quien afirma que son recursos que utilizan los hablantes para alcanzar ciertos objetivos. Wodak (2000) las describe como un plan de acción, y Pardo Abril (2012) refiere que son mecanismos que se constituyen multidisciplinariamente para quienes se interesan en dar cuenta de las problemáticas sociales que enfrenta la sociedad. Las estrategias encontradas en los discursos son la argumentación, la legitimación, la deslegitimación, sustitución y naturalización; construidas a partir de recursos lingüísticos (eufemismos, cuantificadores, interrogaciones y formas verbales); discursivos (acusación-justificación, negociación, ocultamiento, persuasión y mitigación) y retóricos (metáfora, personificación, hipérbole, símil o comparación).

Para dar cuenta de cómo se manifiesta el lenguaje metafórico en estos discursos, se analizan los recursos retóricos como modos de expresión que hacen uso especial del lenguaje con fines expresivos o estilísticos. Lakoff y Johnson (1995) consideran que la esencia de la metáfora es entender y experimentar una cosa en términos de otra, y que nuestra cotidianidad está impregnada de metáforas mediante las cuales se crea y se recrea la realidad. Desde esta perspectiva, se analizan las siguientes clases de metáforas: de canal, estructurales, orientacionales, ontológicas y de recipiente.

La presente investigación es relevante, ya que interpreta el discurso -uso del lenguaje- en el habla como una construcción social, y desde la perspectiva de Van Dijk (2005), esto implica reconocer que el discurso no solo está surtido de distintos niveles de estructura, sino que se hace indispensable significarlo como un fenómeno práctico, social y cultural. Por ello, no se le puede tomar como un simple material textual, sino como un mecanismo que constituye acciones y prácticas del lenguaje que reproducen, transforman, legitiman y alteran el orden social.

\section{Metodología}

\subsection{El corpus}

Para la selección del corpus, se realizó un rastreo de noticias referentes al proceso de paz a través de la revista virtual Semana, periódicos El Tiempo y Vanguardia Liberal, en el periodo comprendido entre enero y octubre del año 2012. Después de realizar una exploración de distintas noticias para determinar aquellas que mostraran concretamente las propuestas del Gobierno y de las FARC para alcanzar el fin del conflicto armado, se seleccionó la noticia del 18 de octubre del 2012, publicada en la revista virtual Semana 
por contener el discurso íntegro de las FARC y del Gobierno en la instalación de la mesa de diálogos; situación que daría inicio formal a las conversaciones para el proceso de paz.

La metodología seguida en la investigación está dada en dos fases: una exploratoria descriptiva y otra analítica. En la primera fase se recopiló y se seleccionó el corpus, luego se realizó una exploración de este a través del programa informático NVivo 10. En la segunda fase, se hizo un análisis cualitativo de los recursos lingüísticos que coadyuvarían en la construcción de las estrategias discursivas presentes, luego se realizó una interpretación para poner en relación lo que va del discurso a la sociedad y de la sociedad al discurso, con el fin de mirar cómo el discurso construye diferentes formas de representación de la realidad relacionadas con el ejercicio de poder. Lo que se busca con la interpretación es inferir y hacer explícitos los significados que portan los discursos, para luego conceptualizar el proceso de paz en Colombia, establecer semejanzas y diferencias entre los discursos y determinar las implicaciones sociopolíticas que se derivan de dicho análisis.

La investigación se soporta en los enfoques cuantitativo y cualitativo, con un paradigma hermenéutico (interpretativo-crítico), ya que interpreta el lenguaje como un fenómeno social, con el fin de analizar y dar sentido al acto comunicativo que se presenta; lo que implica para el analista, no solo quedarse con el contenido explícito del discurso, sino hacer una interpretación que permita trascender e ir más allá del texto para ampliar el marco de significaciones y ver otras realidades generadas a partir del análisis

El enfoque cuantitativo se complementa con el cualitativo, debido a que los insumos obtenidos de la saliencia cuantitativa son objeto de análisis desde una perspectiva cualitativa (Pardo Abril, 2012), para después realizar un análisis interpretativo-crítico de los resultados. En este sentido, el paradigma hermenéutico-crítico que soporta la investigación permite que los discursos textuales sean comprendidos a partir de la interpretación intencional y contextual, en la medida que se va más allá de la palabra para captar su sentido. En el decir de Martyniuk (1994, p. 69), la hermenéutica rompe con los elementos simbólicos de una cultura y con las interpretaciones del mundo que hemos construido, pues el proceso interpretativo cambia la manera de concebir algunas significaciones y crea conocimiento diferente en la sociedad.

\section{Resultados}

\section{Primera fase: análisis cuantitativo}

Para la identificación y caracterización de las unidades de análisis, se elaboró una lista de ocurrencias y sus frecuencias como se muestra en las tablas 1 y 2 , es decir, el número de veces que se repite una palabra, un segmento de texto, una figura retórica; 
con el fin de dar cuenta del dominio cognitivo que se propone en los discursos y de la complejidad conceptual. Este ejercicio permitió hacer un acercamiento a las unidades relevantes, dado que ello admite realizar comparaciones entre los elementos del corpus.

Tabla 1. Palabras más frecuentes del corpus (discurso de Humberto de La Calle Lombana)

\begin{tabular}{|l|c|c|c|l|c|c|c|}
\hline \multicolumn{1}{|c|}{ Palabra } & Longitud & Conteo & $\mathbf{( \% )}$ & \multicolumn{1}{c|}{ Palabra } & Longitud & Conteo & (\%) \\
\hline Farc & 4 & 14 & 0,92 & Nuestras & 8 & 4 & 0,26 \\
\hline Gobierno & 8 & 14 & 0,92 & Opinión & 7 & 4 & 0,26 \\
\hline Proceso & 7 & 13 & 0,85 & Oportunidad & 11 & 4 & 0,26 \\
\hline También & 7 & 13 & 0,85 & Partes & 6 & 4 & 0,26 \\
\hline Conflicto & 9 & 11 & 0,72 & Participación & 13 & 4 & 0,26 \\
\hline Conversaciones & 14 & 8 & 0,53 & Punto & 5 & 4 & 0,26 \\
\hline Acuerdo & 7 & 7 & 0,46 & Quiero & 6 & 4 & 0,26 \\
\hline Agenda & 6 & 7 & 0,46 & Terminación & 11 & 4 & 0,26 \\
\hline Colombia & 8 & 7 & 0,46 & Acordado & 8 & 3 & 0,20 \\
\hline Fase & 4 & 7 & 0,46 & Apoyo & 5 & 3 & 0,20 \\
\hline Paz & 3 & 7 & 0,46 & Armado & 6 & 3 & 0,20 \\
\hline Política & 8 & 6 & 0,39 & Armas & 5 & 3 & 0,20 \\
\hline Acuerdos & 8 & 5 & 0,33 & Cambios & 7 & 3 & 0,20 \\
\hline Esencial & 8 & 5 & 0,33 & Confidencialidad & 16 & 3 & 0,20 \\
\hline Ideas & 5 & 5 & 0,33 & Conscientes & 11 & 3 & 0,20 \\
\hline Mecanismos & 10 & 5 & 0,33 & Democracia & 10 & 3 & 0,20 \\
\hline Mesa & 4 & 5 & 0,33 & Desarrollo & 10 & 3 & 0,20 \\
\hline Poder & 5 & 5 & 0,33 & Diálogos & 8 & 3 & 0,20 \\
\hline Queremos & 8 & 5 & 0,33 & Durante & 7 & 3 & 0,20 \\
\hline Sabemos & 7 & 5 & 0,33 & Esfuerzo & 8 & 3 & 0,20 \\
\hline Comienza & 8 & 4 & 0,26 & Esperanza & 9 & 3 & 0,20 \\
\hline Creemos & 7 & 4 & 0,26 & Final & 5 & 3 & 0,20 \\
\hline Delegación & 10 & 4 & 0,26 & Fondo & 5 & 3 & 0,20 \\
\hline Hoy & 3 & 4 & 0,26 & Garantes & 8 & 3 & 0,20 \\
\hline
\end{tabular}

Tabla 2. Palabras más frecuentes en el discurso de Iván Márquez

\begin{tabular}{|l|c|c|c|l|c|c|c|}
\hline \multicolumn{1}{|c|}{ Palabra } & Longitud & Conteo & $\mathbf{( \% )}$ & Palabra & Longitud & Conteo & $\mathbf{( \% )}$ \\
\hline Paz & 3 & 62 & 0,95 & Patria & 6 & 12 & 0,18 \\
\hline Colombia & 8 & 50 & 0,76 & Política & 8 & 12 & 0,18 \\
\hline Pueblo & 6 & 34 & 0,52 & Proyecto & 8 & 12 & 0,18 \\
\hline Millones & 8 & 32 & 0,49 & Transnacional & 13 & 12 & 0,18 \\
\hline Nuestro & 7 & 30 & 0,46 & Causa & 5 & 10 & 0,15 \\
\hline Territorio & 10 & 24 & 0,37 & Economía & 8 & 10 & 0,15 \\
\hline
\end{tabular}




\begin{tabular}{|l|c|c|c|l|c|c|c|}
\hline \multicolumn{1}{|c|}{ Palabra } & Longitud & Conteo & $\mathbf{( \% )}$ & Palabra & Longitud & Conteo & $\mathbf{( \% )}$ \\
\hline País & 4 & 22 & 0,34 & Hectáreas & 9 & 10 & 0,15 \\
\hline Gobierno & 8 & 20 & 0,31 & Minero & 6 & 10 & 0,15 \\
\hline Tierras & 7 & 20 & 0,31 & Oro & 3 & 10 & 0,15 \\
\hline Estado & 6 & 18 & 0,27 & Población & 9 & 10 & 0,15 \\
\hline Farc & 4 & 18 & 0,27 & Pueblos & 7 & 10 & 0,15 \\
\hline Nuestra & 7 & 18 & 0,27 & Puede & 5 & 10 & 0,15 \\
\hline Años & 4 & 16 & 0,24 & Sangre & 6 & 10 & 0,15 \\
\hline Conflicto & 9 & 16 & 0,24 & Simón & 5 & 10 & 0,15 \\
\hline Mundo & 5 & 16 & 0,24 & Sociales & 8 & 10 & 0,15 \\
\hline Nacional & 8 & 16 & 0,24 & Solución & 8 & 10 & 0,15 \\
\hline Tierra & 6 & 16 & 0,24 & Suelo & 5 & 10 & 0,15 \\
\hline Guerra & 6 & 14 & 0,21 & Transnacionales & 15 & 10 & 0,15 \\
\hline Justicia & 8 & 14 & 0,21 & Violencia & 9 & 10 & 0,15 \\
\hline Mesa & 4 & 14 & 0,21 & Campesina & 9 & 8 & 0,12 \\
\hline Mil & 3 & 14 & 0,21 & Campo & 5 & 8 & 0,12 \\
\hline Resistencia & 11 & 14 & 0,21 & Colombiano & 10 & 8 & 0,12 \\
\hline Soberanía & 9 & 14 & 0,21 & Derecho & 7 & 8 & 0,12 \\
\hline Social & 6 & 14 & 0,21 & Diálogos & 8 & 8 & 0,12 \\
\hline Campesinos & 10 & 12 & 0,18 & Militar & 7 & 8 & 0,12 \\
\hline Colombianos & 11 & 12 & 0,18 & Militares & 9 & 8 & 0,12 \\
\hline Lucha & 5 & 12 & 0,18 & Nación & 6 & 8 & 0,12 \\
\hline Nuestros & 8 & 12 & 0,18 & Nuestras & 8 & 8 & 0,12 \\
\hline
\end{tabular}

La reiteración frecuente de algunas palabras constituye la ocurrencia, la cual hace posible determinar la frecuencia alta, media o baja. Además, posibilita el reconocimiento de asociaciones semánticas y formas particulares de elaborar acuerdos o desacuerdos. En el discurso de Humberto de La Calle Lombana (Tabla 1), se puede determinar que las palabras de frecuencia alta son: FARC, con $0,92 \%$; Gobierno, con $0,92 \%$ y proceso, con 0,85\%. En el discurso de Iván Márquez (Tabla 2), son: paz, con una frecuencia de 0.95\%; en orden descendente aparece Colombia, con el $0.76 \%$. Por ser estas palabras las de mayor ocurrencia, se infiere que la unidad temática principal en el discurso de Humberto de La Calle Lombana es el proceso entre Gobierno y FARC, y en el de Iván Márquez corresponde a la paz en Colombia.

La frecuencia de las unidades léxicas no es suficiente para el análisis, por eso fue necesario determinar la concurrencia de estas palabras mediante los co-textos o conjunto de unidades linguísticas que anteceden y siguen de manera inmediata a estas palabras (Tablas 3, 4 y 5). Esta representación permite desentrañar el sentido que obtienen estas expresiones y el realce semántico que poseen en el discurso. 
Tabla 3. Concordancias de "Gobierno" en el discurso de Humberto de La Calle Lombana

\begin{tabular}{|c|c|c|}
\hline CO-TEXTO ANTERIOR & PALABRA & CO-TEXTO POSTERIOR \\
\hline $\begin{array}{l}\text { Hacemos presencia en Oslo para dar } \\
\text { comienzo a la fase } 2 \text { del proceso de } \\
\text { conversaciones entre el }\end{array}$ & Gobierno & y las Farc- EP \\
\hline La delegación del & Gobierno & $\begin{array}{l}\text { colombiano presenta un saludo de } \\
\text { agradecimiento }\end{array}$ \\
\hline $\begin{array}{l}\text { De manera clara queremos reconocer que } \\
\text { las Farc han cumplido rigurosamente sus } \\
\text { compromisos. El }\end{array}$ & Gobierno & $\begin{array}{l}\text { también lo ha hecho, pese a las diversas } \\
\text { complejidades logísticas superadas de } \\
\text { manera eficiente con la ayuda de los países } \\
\text { garantes }\end{array}$ \\
\hline $\begin{array}{l}\text { La oportunidad de las propuestas es } \\
\text { también esencial. La opinión pública es un } \\
\text { elemento que importa al }\end{array}$ & Gobierno & desde esquema político democrático \\
\hline $\begin{array}{l}\text { La fase } 3 \text { es el escenario para las } \\
\text { transformaciones necesarias que serán el } \\
\text { verdadero motor de la paz. El }\end{array}$ & Gobierno & $\begin{array}{l}\text { ha puesto en marcha una agenda audaz } \\
\text { para introducir cambios sociales profundos } \\
\text { en nuestra sociedad }\end{array}$ \\
\hline Tiene una agenda progresista. El & Gobierno & $\begin{array}{l}\text { ha reconocido la inequidad y la desigualdad } \\
\text { existente en Colombia, pero no se limita al } \\
\text { diagnóstico. }\end{array}$ \\
\hline $\begin{array}{l}\text { Creemos que escribir leyes agota las } \\
\text { soluciones. Y ello no es así, no es así. El }\end{array}$ & Gobierno & quiere trabajar en el plano de la realidad. \\
\hline $\begin{array}{l}\text { El derecho de tutela hace que el último juez } \\
\text { tenga más poder que todo el }\end{array}$ & Gobierno & en la rama ejecutiva. \\
\hline Por lo tanto, como ya dije el deseo del & Gobierno & $\begin{array}{l}\text { reconocer los puntos de la agenda, los } \\
\text { cuales deben ser la guía de nuestras } \\
\text { conversaciones. }\end{array}$ \\
\hline $\begin{array}{l}\text { Aunque quien les habla estuvo } \\
\text { comprometido a fondo en esa tarea, quiero } \\
\text { reconocer hoy que, en la medida de las } \\
\text { conversaciones, el }\end{array}$ & Gobierno & $\begin{array}{l}\text { está dispuesto a profundizar ese camino } \\
\text { y a ampliar el horizonte, a examinar los } \\
\text { aciertos, pero también aquellas práctica e } \\
\text { instituciones insuficientes }\end{array}$ \\
\hline
\end{tabular}

Tabla 4. Concordancias de "FARC" en el discurso de Humberto de La Calle Lombana

\begin{tabular}{|l|l|l|}
\hline \multicolumn{1}{|c|}{ CO-TEXTO ANTERIOR } & PALABRA & \multicolumn{1}{|c|}{ CO-TEXTO POSTERIOR } \\
\hline $\begin{array}{l}\text { Buenos días. Bajo el liderazgo del } \\
\text { presidente Juan Manuel Santos, hacemos } \\
\text { presencia en Oslo para dar comienzo a la } \\
\text { fase 2 del proceso de conversaciones entre } \\
\text { el Gobierno y las }\end{array}$ & FARC & $\begin{array}{l}\text { La delegación del Gobierno colombiano } \\
\text { presenta un saludo de agradecimiento a } \\
\text { los gobiernos }\end{array}$ \\
\hline $\begin{array}{l}\text { De manera clara queremos reconocer que } \\
\text { las }\end{array}$ & FARC & $\begin{array}{l}\text { han cumplido rigurosamente sus } \\
\text { compromisos }\end{array}$ \\
\hline
\end{tabular}




\begin{tabular}{|l|c|l|}
\hline \multicolumn{1}{|c|}{ CO-TEXTO ANTERIOR } & PALABRA & \multicolumn{1}{c|}{ CO-TEXTO POSTERIOR } \\
\hline $\begin{array}{l}\text { Pero dentro del ritmo de la negociación, } \\
\text { cada cosa debe suceder en su momento, } \\
\text { esto es importante también para las }\end{array}$ & FARC & $\begin{array}{l}\text { Esa es también una garantía para la } \\
\text { aplicación del principio de que "nada está } \\
\text { acordado si todo no está acordado" }\end{array}$ \\
\hline $\begin{array}{l}\text { En esta mesa deseamos y ofrecemos un } \\
\text { trato recíprocamente digno. Repito que } \\
\text { seguramente no nos vamos a convencer } \\
\text { el uno al otro de nuestras diversas ideas } \\
\text { políticas. Sabemos que las }\end{array}$ & FARC & $\begin{array}{l}\text { tienen una concepción del mundo y la } \\
\text { política, y nuestro propósito no es venir a } \\
\text { catequizar a nadie. }\end{array}$ \\
\hline $\begin{array}{l}\text { Hay un punto en el que coincidimos con las } \\
\text { Hoy hay en marcha una transformación de } \\
\text { la realidad social en Colombia. Y las }\end{array}$ & FARC & $\begin{array}{l}\text { la finalización del conflicto no es en sí } \\
\text { misma la consecución inmediata de la paz. }\end{array}$ \\
\hline $\begin{array}{l}\text { La fase 3 es la oportunidad para los } \\
\text { cambios. No para que las }\end{array}$ & FARC & $\begin{array}{l}\text { tienen la posibilidad de unirse a ella, } \\
\text { sin dejar su condición de contraparte al } \\
\text { sistema, para catalizar el proceso }\end{array}$ \\
\hline $\begin{array}{l}\text { De lo que se trata es de mirar que hay } \\
\text { mucho por hacer y queremos invitar a las }\end{array}$ & FARC & $\begin{array}{l}\text { depongan sus ideas, no se trata de eso, } \\
\text { dino para que sigan luchando por ellas en } \\
\text { democracia. }\end{array}$ \\
\hline $\begin{array}{l}\text { Queremos asegurar y escucharemos con } \\
\text { toda atención las opiniones de las } \\
\text { plegarse a nuestras ideas. }\end{array}$ & FARC & $\begin{array}{l}\text { en este punto. Pero igualmente somos } \\
\text { conscientes de que la participación política } \\
\text { también tiene otra perspectiva. }\end{array}$ \\
\hline $\begin{array}{l}\text { Con el deseo ferviente de acertar, } \\
\text { saludamos a los países acompañantes, a } \\
\text { los garantes, a la delegación de las }\end{array}$ & FARC & $\begin{array}{l}\text { en la esperanza de que muy pronto } \\
\text { tengamos noticias excelentes para todos } \\
\text { los colombianos }\end{array}$ \\
\hline
\end{tabular}

Tabla 5. Concordancias de "Colombia” en el discurso de Iván Márquez

\begin{tabular}{|l|l|l|}
\hline \multicolumn{1}{|c|}{ CO-TEXTO ANTERIOR } & PALABRA & \multicolumn{1}{c|}{ CO-TEXTO POSTERIOR } \\
\hline $\begin{array}{l}\text { Señoras y señores, amigas y amigos de } \\
\text { la paz en }\end{array}$ & Colombia & Compatriotas: \\
\hline Dentro de esta dinámica en & Colombia & $\begin{array}{l}\text { el régimen asesina no solo con sus planes de } \\
\text { guerra, con sus paramilitares y sicarios, sino } \\
\text { también con sus políticas económicas que } \\
\text { matan de hambre. }\end{array}$ \\
\hline Esta es una lucha de toda & Colombia & $\begin{array}{l}\text { no obstante, nuestra determinación tiene la } \\
\text { fortaleza para enfrentar a los guerreristas } \\
\text { que creen que con el estruendo de bombas y } \\
\text { de cañones pueden doblegar la voluntad de } \\
\text { quienes mantenemos en alto las banderas del } \\
\text { cambio y la justicia social. }\end{array}$ \\
\hline $\begin{array}{l}\text { Venimos aquí a buscar la victoria de la } \\
\text { solución política sobre la guerra civil } \\
\text { que destroza a }\end{array}$ & Colombia \\
\hline
\end{tabular}




\begin{tabular}{|l|l|l|}
\hline \multicolumn{1}{|c|}{ CO-TEXTO ANTERIOR } & PALABRA & \multicolumn{1}{|c|}{ CO-TEXTO POSTERIOR } \\
\hline El gasto militar en & Colombia & $\begin{array}{l}\text { es de los más altos del mundo en proporción al } \\
\text { producto interno bruto. }\end{array}$ \\
\hline descontando que & Colombia & $\begin{array}{l}\text { es el tercer receptor de ayuda militar } \\
\text { estadounidense en el mundo. }\end{array}$ \\
\hline $\begin{array}{l}\text { Nosotros hacemos un llamado a los } \\
\text { soldados de }\end{array}$ & Colombia & a los oficiales y suboficiales \\
\hline $\begin{array}{l}\text { Con un proyecto de país esbozado en } \\
\text { la Plataforma Bolivariana por la Nueva }\end{array}$ & Colombia & $\begin{array}{l}\text { y nos anima la convicción de que nuestro puerto } \\
\text { es la paz. }\end{array}$ \\
\hline $\begin{array}{l}\text { De los esfuerzos de todos y de la } \\
\text { solidaridad del mundo depende el } \\
\text { destino de }\end{array}$ & Colombia & $\begin{array}{l}\text { Que la oración por la paz de Jorge Eliecer Gaitán } \\
\text { iluminen nuestro camino. }\end{array}$ \\
\hline $\begin{array}{l}\text { Todos por la solución del conflicto } \\
\text { colombiano. jviva }\end{array}$ & Colombia! & iviva Manuel Marulanda Vélez! \\
\hline
\end{tabular}

Las tablas de co-texto ${ }^{1}$ anteriores permiten determinar que la ocurrencia de estas unidades lingüísticas no da cuenta de un actor social específico (Gobierno, FARC, Colombia), sino que lo personaliza a través de instituciones que se hacen responsables del proceso que comienza para alcanzar la paz en Colombia.

Al analizar el comportamiento de estas unidades léxicas dentro del corpus, es evidente la presencia de la sustitución como estrategia discursiva, pues se modifican las formas de representación de los actores mediante el proceso de personalización, dado que estos se presentan como seres humanos. El proceso lingüístico implicado en esta estrategia incluye una forma de encadenamiento lingüístico de nominación llamado supresión, ya que al nominar "Gobierno, FARC y Colombia" como actores sociales, se ocultan sujetos reconocibles a quienes se les pueden atribuir responsabilidades en lo que tiene que ver con el desarrollo del proceso. Cada organización suplanta los nombres propios de los agentes de la acción. Es así como esta estrategia permite recurrir a un saber compartido, según el cual se puede determinar qué actores están ocultos, dado que ya se conocen por la divulgación de otras noticias relacionadas con el proceso de paz.

Las unidades lingüísticas analizadas admiten inferir que, en los discursos de apertura de los diálogos de paz, se evaden responsabilidades sociales de personas concretas que hacen parte de estas organizaciones y que deben asumir acciones para llevar avante el proceso. Se propone un proceso de paz del que se esperan resultados que beneficien a toda la sociedad colombiana; sin embargo, el análisis permite elaborar una presuposición:

1 Como lo muestran las tablas 3, 4 y 5, el co-texto anterior y posterior recoge las concordancias más frecuentes para determinar las unidades léxicas más relevantes. 
"que este no está en las manos de nadie"; por lo tanto, no es posible derivar alguna responsabilidad social.

\section{Segunda fase: análisis cualitativo}

\section{Discurso de Humberto de La Calle Lombana}

Desde el punto de vista retórico, el discurso de Humberto de La Calle Lombana recurre a una serie de técnicas o recursos que permiten hacerlo más convincente frente a los interlocutores. La metáfora es un recurso recurrente en este discurso, dado que se convierte, en primer lugar, en una estrategia para conceder a las palabras la formalidad que se espera de una persona que ejerce un cargo de tan alta responsabilidad (delegado del Gobierno Nacional), por este motivo, el lenguaje es metódico. En segundo lugar, evidencia un fin didáctico, de tal manera que a través de la abundancia de expresiones metafóricas se logra hacer más comprensible un asunto de la vida pública como es el proceso de paz. El fin primordial es tratar de convencer sobre la veracidad de las propuestas que plantea el Gobierno respecto a dicho proceso.

Para identificar las metáforas presentes en el discurso, se tuvo en cuenta la clasificación propuesta por Lakoff y Johnson (1995) en lo que tiene que ver con metáforas ontológicas ${ }^{2}$ y estructurales (Tablas 6 y 7 ).

Tabla 6. Metáforas ontológicas en el discurso de Humberto de La calle Lombana

\begin{tabular}{|c|l|l|}
\hline \multirow{2}{*}{ RECURSO } & \multicolumn{1}{|c|}{ SUJETO } & \multicolumn{1}{|c|}{ ACCIONES HUMANAS QUE SE LE ATRIBUYEN } \\
\hline \multirow{4}{*}{ PERSONIFICACIÓN } & Noruega & $\begin{array}{l}\text { Juega un papel importante dentro del proceso } \\
\text { Ha dado muestra de profesionalismo } \\
\text { Ha generado confianza }\end{array}$ \\
\cline { 2 - 3 } & Cuba & \multicolumn{1}{|c}{ Juegan un papel importante dentro del proceso } \\
\cline { 2 - 3 } & Chile & \\
\cline { 2 - 3 } & Monezuela & No es una esperanza ingenua \\
\cline { 2 - 3 } & El narcotráfico & Genera desconfianza \\
\cline { 2 - 3 } & La opinión & Apoya el proceso \\
\cline { 2 - 3 } & Hay una oportunidad & pero las oportunidades se van \\
\cline { 2 - 3 } & Las conversaciones & Marchan por buen camino \\
\hline
\end{tabular}

2 "Las metáforas ontológicas más obvias son aquellas en las que el objeto físico se especifica como una persona. Esto nos permite comprender una amplia diversidad de experiencias con entidades no humanas en términos de motivaciones, características y actividades humanas" (Lakoff y Johnson, 1995, p. 71). 
En el discurso se mencionan términos abstractos que refieren acciones propias de una persona. A través de este recurso de personificación, se construye la estrategia de ocultamiento, ya que se da a conocer los países participantes en el proceso de paz, pero a la vez se desconocen los nombres de los personajes que estarán directamente involucrados en dicho proceso.

\section{Tabla 7. Metáforas estructurales ${ }^{3}$}

\begin{tabular}{|c|c|}
\hline $\begin{array}{l}\text { La mesa de diálogo } \\
\text { es un ser humano }\end{array}$ & $\begin{array}{l}\text { La mesa de negociación para el proceso de paz se describe con características } \\
\text { propias de una persona, al usar expresiones como "desarrollo de la mesa", } \\
\text { "contenidos de la mesa", "necesidades de la mesa", las cuales se hallan } \\
\text { vinculadas a este concepto metafórico. }\end{array}$ \\
\hline $\begin{array}{l}\text { El conflicto es una } \\
\text { enfermedad }\end{array}$ & $\begin{array}{l}\text { En el discurso se apela a una metáfora médica, de tal manera que Colombia se } \\
\text { convierte en una especie de cuerpo físico, enfrentado a un problema, el cual es } \\
\text { posible atacar a través de diversas intervenciones. Esto es evidente cuando se } \\
\text { menciona que el Gobierno "no se limita al diagnóstico", "examinar los aciertos, } \\
\text { pero también aquellas prácticas e instituciones insuficientes"; además, desea } \\
\text { "garantizar la vida", "momento de esperanza. No es una esperanza ingenua", } \\
\text { "tenemos una dosis de optimismo", "vinimos a hacer nuestro mejor esfuerzo" }\end{array}$ \\
\hline $\begin{array}{l}\text { El proceso de } \\
\text { paz es una } \\
\text { construcción }\end{array}$ & $\begin{array}{l}\text { "Quiero referirme un poco, en primer lugar, a la estructura del proceso". "Hoy } \\
\text { hay en marcha una transformación social de la realidad social en Colombia". } \\
\text { "Creemos que escribir leyes agota las soluciones. Y ello no es así, no es así. El } \\
\text { gobierno quiere trabajar en el plano de la realidad" }\end{array}$ \\
\hline $\begin{array}{l}\text { La paz es un } \\
\text { vehículo }\end{array}$ & $\begin{array}{l}\text { El concepto metafórico se evidencia cuando se hace alusión al "verdadero motor" } \\
\text { refiriéndose a un instrumento de la mecánica que contribuirá al movimiento de } \\
\text { un objeto. Cuando se menciona el término "verdadero" se sobreentiende que } \\
\text { existen varios elementos, pero solo uno será el que se acomode y logre dar el } \\
\text { adecuado funcionamiento: "Hay un punto en el que coincidimos con las FARC: } \\
\text { la finalización del conflicto no es en sí la misma consecución inmediata de la } \\
\text { paz. La fase } 3 \text { es el escenario para las transformaciones necesarias que serán el } \\
\text { verdadero motor de la paz" }\end{array}$ \\
\hline
\end{tabular}

\section{Estrategias discursivas}

Los recursos presentes en el discurso como eufemismos, metáforas, hipérboles, repeticiones contribuyen a la construcción de la estrategia argumentativa. El uso de premisas está dirigido a obtener conclusiones de mutuo acuerdo, además, de ser una representación de lo verosímil o probable, cuyo propósito es alcanzar formas de adhesión sobre lo que se representa.

3 Las metáforas estructurales se evidencian cuando se estructura un concepto en términos de otro, puede ser comparando dos realidades abstractas o cotejando una realidad abstracta con una concreta. 
En el discurso de Humberto de La Calle Lombana, es recurrente la justificación de los puntos de vista que adopta el Gobierno con el propósito de intentar resolver y enfrentar una diferencia de opinión con las FARC. Se acude al recurso de persuasión como un mecanismo para influenciar a las FARC, con llamamientos dirigidos que se dan en tres fases: en primer lugar, informa sobre situaciones del país, después argumenta sobre hechos informados y probados, para luego intentar que las FARC se adhiera a sus planteamientos.

Según Pardo Abril (2007), la estrategia de naturalización ${ }^{4}$ se constituye al asignarle representación discursiva de existencia a un objeto o fenómeno de la realidad, en este caso se evidencia cuando aparece la expresión linguística "confrontación estéril". El recurso de biologización se conforma a través de esta figura para que se interprete el proceso de paz como algo productivo en términos de pensamiento y acción. Los recursos de ocultamiento y presuposición contribuyen también a la construcción de esta estrategia.

La estrategia de legitimación (Van Dijk, 1998) es evidente, dado que el Gobierno busca la aprobación moral como respuesta a una serie de situaciones que ponen en riesgo su institucionalidad. Entonces, intenta modificar la posición de las FARC como otro grupo que también ejerce poder y de alguna manera toma parte en las propuestas que se plantean.

El discurso promulgado por Humberto de La Calle Lombana pretende establecer un consenso sobre la realidad del país y, a través del proceso linguístico de negociación (Pardo Abril, 2007), pone en escena el poder que ejerce el Gobierno, y en consecuencia, sus intereses con respecto a la resolución del conflicto armado. Para persuadir y lograr la adhesión de las FARC como grupo opositor, se recurre a un lenguaje metafórico y al uso de eufemismos para evitar referencias directas que resulten demasiado reveladoras y para ocultar intenciones que puedan dar lugar a posibles cuestionamientos. Reduciendo así el papel que le corresponde como agente responsable; de esta manera, se construye la estrategia de mitigación.

\section{Discurso de Iván Márquez}

En el discurso son evidentes los recursos retóricos como hipérboles, símiles, metonimias y, principalmente, metáforas. A continuación, se muestran algunos ejemplos, desde la perspectiva de Lakoff y Johnson (1995).

4 Consiste en atribuir a los procesos sociales la estabilidad que comúnmente se asocia al mundo de los objetos físicos y biológicos (Pardo, 2012, p. 157). 
Tabla 8. Metáforas Ontológicas

\begin{tabular}{|c|c|c|}
\hline RECURSO & SUJETO & ACCIONES HUMANAS QUE SE LE ATRIBUYEN \\
\hline \multirow{7}{*}{ Personificación } & La paz & $\begin{array}{l}\text { por sus afanes solo conduciría a los precipicios de la } \\
\text { frustración }\end{array}$ \\
\hline & La paz & es una veleidad \\
\hline & La titulación & $\begin{array}{l}\text { No es más que la legalidad que pretende lavar el rostro } \\
\text { ensangrentado del despojo }\end{array}$ \\
\hline & El mercado & desenmascarar a ese asesino metafísico \\
\hline & Neoliberalismo & $\begin{array}{l}\text { Sentar al neoliberalismo en el banquillo de los } \\
\text { acusados como verdugo de pueblos y fabricante } \\
\text { de muerte }\end{array}$ \\
\hline & Colombia & ¡Pobre Colombia! \\
\hline & Régimen & asesina \\
\hline
\end{tabular}

Las metáforas se construyen con el recurso de personificación, puesto que se le asigna a términos abstractos acciones propias del ser humano. Aquí es evidente la estrategia de ocultamiento, ya que se omiten los sujetos responsables de dichas acciones.

Con la metáfora "el régimen asesina" se oculta los actores sociales responsables de la elaboración de las leyes que reglamentan las políticas económicas del Estado y se le atribuye el adjetivo de asesino, con lo que se califican estas políticas como peligrosas, ya que acaban con la prosperidad del país. En la expresión metafórica: "Hoy hemos venido a desenmascarar a ese asesino metafísico que es el mercado", se reitera el atributo de asesino, es decir, que para las FARC la economía del país es un ser pensante con una ideología nefasta que conduce al detrimento y muerte de la población, por tanto se debe detener.

El neoliberalismo es un modelo económico con una amplia liberalización de la economía, el libre comercio y una reducción exagerada del gasto público, en donde el Estado interviene a favor del sector privado. Con la metáfora "sentar al neoliberalismo en el banquillo de los acusados como verdugo de pueblos y fabricación de muerte", se muestra al neoliberalismo como un ser que tiene la facultad de sentarse para ser acusado y se le atribuye el adjetivo de verdugo y fabricante de muerte, o sea que es un ser duro y sanguinario con una filosofía peligrosa que conlleva detrimento de la economía de un país.

En la expresión: “PPobre Colombia! obligada a competir con las transnacionales”, la metáfora muestra al país como un ser débil, enfermizo, que inspira lástima y es incapaz de 
mantener una buena economía. El dominio origen de la metáfora es pobreza y el dominio destino es Colombia, o sea Colombia es un sujeto necesitado.

\section{Estrategias discursivas}

Estrategia de naturalización: se construye en el discurso a través de recursos retóricos como el símil, la metáfora y la hipérbole: "Necesitamos edificar la convivencia sobre bases pétreas como los inamovibles fiordos rocosos de estas tierras, para que la paz sea estable y duradera". La metáfora conceptualiza la convivencia como un acontecimiento físico similar a una casa que se construye sobre piedras. La hipérbole señala que es algo sumamente difícil de llevar a cabo, porque nadie construye sobre un acantilado, de lo que se infiere que para las FARC, la paz es imposible de lograr. Este hecho se presenta en el discurso como algo natural y obvio, por tanto, normal e incuestionable; de esta manera, se oculta la responsabilidad que tienen las FARC en este acontecimiento social tan importante como es la paz.

Estrategia de argumentación: la autorización es un recurso lingüístico que constituye la estrategia de argumentación, puesto que Iván Márquez tiende a persuadir con la información presentada en forma clara, breve y verosímil; valiéndose de expresiones y opiniones de un personaje ilustre de reconocimiento social como el líder político Simón Bolívar, para enfatizar el valor que tiene la tierra, por ser el lugar donde se ha nacido y vivido. Toca las emociones y los sentimientos del interlocutor para suscitar aceptación y legitimar su imagen basado en el ideal de un territorio libre de violencia.

Al respecto deberíamos interiorizar la profunda definición del Libertador Simón Bolívar sobre lo que es Patria, nuestro suelo, nuestro territorio:

"Primero el suelo nativo que nada nos dice, él ha formado con sus elementos nuestro ser. Nuestra vida no es otra cosa que la esencia de nuestro propio país. Allí se encuentran los testigos de nuestro nacimiento, los creadores de nuestra existencia y los que nos han dado alma para la educación. Los sepulcros de nuestros padres yacen allí y nos reclaman seguridad y reposo. Todo nos recuerda un deber, todo nos excita sentimientos tiernos y memorias deliciosas. Allí fue el teatro de nuestra inocencia, de nuestros primeros amores, de nuestras primeras sensaciones y de cuanto nos ha formado. Que títulos más sagrados al amor y a la consagración" (Iván Márquez, 2012)

Estrategia de legitimación: se construye a partir de procesos lingüísticos de persuasión y acusación-justificación. Se hace uso del recurso de la cuantificación con el propósito de justificar el accionar de las FARC en el conflicto armado. 
Tabla 9. Cuantificadores en el discurso de Iván Márquez

\begin{tabular}{|c|l|}
\hline $\begin{array}{c}\text { Recurso } \\
\text { lingüístico }\end{array}$ & \multicolumn{1}{|c|}{ Párrafos del discurso donde son reiterativos los cuantificadores } \\
\hline & $\begin{array}{l}\text { No se puede encadenar este proceso a una política enfocada exclusivamente en la obtención } \\
\text { desaforada de ganancias para unos pocos capitalistas a los que no les importa para nada la } \\
\text { pobreza que abate al 70\% de la población. Ellos solo piensan en el incremento de su botín, } \\
\text { no en la reducción de la miseria. }\end{array}$ \\
\hline $\begin{array}{l}\text { Más de } \mathbf{3 0} \text { millones de colombianos viven en la pobreza, } \mathbf{1 2} \text { millones en la indigencia, } \\
\text { el } \mathbf{5 0 \%} \text { de la población económicamente activa agoniza entre el desempleo y el subempleo. } \\
\text { Casi seis millones de campesinos deambulan por las calles víctimas del desplazamiento } \\
\text { forzoso. De 144 millones de hectáreas que tiene el país, } \mathbf{3 8} \text { millones están asignados a la } \\
\text { exploración petrolera, } \mathbf{1 1} \text { millones a la minería. De las } \mathbf{7 5 0} \text { mil hectáreas en explotación } \\
\text { forestal se proyecta pasar a } \mathbf{1 2} \text { millones. }\end{array}$ \\
$\begin{array}{l}\text { La ganadería ocupa 39,2 millones. El área cultivable es } \mathbf{2 1 , 5} \text { millones de hectáreas, pero } \\
\text { solamente 4,7 millones de ellas están dedicadas a la agricultura, guarismo en decadencia } \\
\text { porque ya el país exporta diez millones de toneladas de alimentos al año. Más de la mitad } \\
\text { del territorio colombiano está en función de los intereses de una economía enclave. }\end{array}$ \\
$\begin{array}{l}\text { Los mismos datos oficiales cuentan que las fincas de más de } \mathbf{5 0 0} \text { hectáreas corresponden al } \\
\mathbf{0 , 4 \%} \text { de los propietarios que controlan el } \mathbf{6 1 , 2 \%} \text { de la superficie agrícola. Se trata de una } \\
\text { acumulación por desposesión, cuya más reciente referenciahabla de ocho millones dehectáreas } \\
\text { arrebatadas a sangre y fuego a través de masacres paramilitares, fosas comunes, desapariciones, } \\
\text { y desplazamientos forzosos, crímenes de lesa humanidad acentuados durante los ocho años del } \\
\text { gobierno de Uribe. Todos ellos componentes del terrorismo de Estado de Colombia. }\end{array}$ \\
\hline
\end{tabular}

La cuantificación es un recurso lingüístico usado por Iván Márquez para argumentar los factores que han desatado la violencia en Colombia. Los razonamientos expuestos en el discurso cobran validez, ya que se dan cifras exactas que aunque no sean del todo ciertas cumplen con la finalidad de convencer al interlocutor de la veracidad de los argumentos. Se expresa en porcentajes la cifra de los propietarios de la gran mayoría de territorio dedicado a la agricultura colombiana, además, se acusa al Estado colombiano de la desposesión de tierras, apelando a la metáfora "ocho millones de hectáreas arrebatadas a sangre y fuego", con el propósito de resaltar los aspectos negativos del Gobierno y responsabilizarlo de la violencia en el país. Se evidencia el recurso de acusación-justificación, pues las FARC pretenden poner en duda el proceder del Gobierno para desequilibrar el poder de este actor social y cuestionar las acciones que se han llevado a cabo para alcanzar los fines económicos del país. La estrategia toma un matiz polarizante que implica la presentación negativa del otro y positiva del nosotros 5 .

5 Se intenta mostrar que mi grupo posee características positivas en relación con otro que representa lo negativo (Van Dijk, 2008). 


\section{Discusión}

Determinar los recursos y las estrategias lingüísticas permitió inferir que el propósito del Gobierno es presentar el proceso de paz como una construcción que requiere de acciones concretas para su resolución. Sin embargo, el uso del lenguaje metafórico implica dar otro sentido a lo que se propone, pues la estructura del proceso de paz se construye sobre términos abstractos a los cuales se les asignan acciones propias de actores concretos que deberían asumir la responsabilidad en dicho proceso ¿quién es el Gobierno?, ¿quién es las FARC?, ¿quiénes lo representan?, ¿qué acciones le corresponden a cada uno?

Por otro lado, en el discurso de las FARC, la paz se conceptualiza como una reforma a las estructuras del Estado colombiano, en lo referente a las políticas económicas y sociales. En la intervención de Iván Márquez, se logra dilucidar la problemática social que se vive, pues el pueblo es la víctima del modelo económico neoliberal y es visto como "el verdugo de pueblos y fabricante de muerte".

Al contrastar los discursos analizados, es evidente que sus productores orientan cada definición del proceso de paz hacia sus intereses políticos. En el caso de las FARC, ellos reafirman su ideología, encubren sus acciones bélicas y se posicionan como colectivo social que lucha por sus derechos. En cuanto al Gobierno, reivindica su institucionalidad, democracia y plan de gobernabilidad. Cada uno de los actores recurre a estrategias que permiten mostrar sus esfuerzos para justificar sus acciones y decisiones en el conflicto.

La falta de claridad desconcierta a la opinión pública, con su manejo están debilitando el concepto de Estado y se capta el interés de popularidad del presidente que dio un paso osado para el reinicio del proceso. Hay nivelación Estado - FARC, al llamar al diálogo de igual a igual, esto causa impacto porque despierta el interés colectivo por alcanzar la paz en Colombia, pero al final de un periodo presidencial ¿quién responde por los resultados? Los diálogos de paz en Colombia deben dejar un plan político de Estado que no dependa del gobierno en turno, donde el pueblo sea el principal benefactor y no un elemento más de la negociación.

En el discurso de Iván Márquez, se recoge la victimización y eso diluye la responsabilidad de las FARC. Sin embargo, el pueblo colombiano sigue esperando la paz utópica que propone el Gobierno con la búsqueda de "la transformación social".

A la hora de la verdad, los dos discursos son más subjetivos que objetivos porque mientras Iván Márquez reafirma la ideología de las FARC y por medio de ella justifica sus acciones, la contraparte pretende convencer de que el Estado maneja las situaciones y, de esta manera, termina sembrando más dudas que certezas para la parte expectante. 


\section{Conclusiones}

La estrategia de argumentación que predomina en el discurso de Humberto de La Calle Lombana y que se construye con recursos como metáforas, eufemismos, hipérboles y repeticiones, surge con la finalidad de enfrentar e intentar resolver una diferencia de opiniones con las FARC a través de justificaciones de los puntos de vista del Gobierno. Por esta razón, funda argumentos para persuadir de forma diplomática y sutil, sin refutar ni culpar, solo para exhortar y buscar la adhesión y lograr aceptabilidad. Para esto, recurre a mundos simbólicos y construcciones metafóricas que producen un efecto cognitivo en los oyentes y que solo les permite comprender el discurso de forma parcial, pues ni siquiera perciben ni comprenden las imágenes que se presentan como expresiones no literales.

Por otro lado, las FARC legitiman sus posturas y su proceder para desacreditar y culpabilizar al Gobierno del conflicto en Colombia. El discurso está enfocado en argumentar los diferentes hechos que generan la violencia, de la cual es responsable el Estado por sus políticas económicas que favorecen solo a unos pocos. Se hace uso de diferentes recursos discursivos y retóricos con el propósito de legitimar el accionar de las FARC y transformar el consenso, a través de la persuasión, para crear una imagen positiva de este actor social en oposición a la del Gobierno.

Las metáforas son recurrentes y su función es conceptualizar la paz, la economía, las FARC, el Gobierno, Colombia, entre otros. El uso de cuantificadores también es otro recurso lingüístico reiterativo que constituye la estrategia de legitimación, dado que son utilizados para dotar de validez y objetividad los argumentos que pretenden justificar todos los hechos violentos de los cuales ha formado parte las FARC, ocultando su participación y acusando al Estado de ser el responsable.

Los recursos linguísticos tienen diversas finalidades: involucrar a todos los interlocutores en un colectivo social dentro del cual se exhorta a una participación corresponsable; algunos tienen la función de enfatizar aspectos relevantes, otros son usados para ocultar y disfrazar ciertas realidades, para suavizar el impacto, de tal manera que no genere cuestionamientos posteriores.

El presente trabajo pone en relación los recursos lingüístico-discursivos de los que hacen uso los actores involucrados en el proceso de negociación en Oslo (GobiernoFARC) y presenta el resultado de un ejercicio de investigación actual que contribuye a la comprensión de la problemática del conflicto colombiano. Es importante resaltar que estos resultados se constituyen en insumos para futuras investigaciones sobre el Análisis 
Crítico del Discurso político en relación con el análisis de recursos y estrategias discursivas que contribuyen a develar intereses, ideologías y representaciones sociales.

\section{Referencias bibliográficas}

Albert, M. (2007). La investigación Educativa. Claves teóricas. España: McGraw-Hill.

Aparici, R., Fernández, J., Garcia, A., \& Osuna, S. (2006). La imagen. Barcelona: Gedisa.

Arroyo, E. (2010). El discurso político y sus recursos retóricos. Recuperado de http:// elnuevodiario.com.do/app/article.aspx?id=206761

Bosque, I., \& Demonte, V. (1999). Gramática descriptiva de la lengua española (tomos 1, 2, 3) Madrid: Espasa Calpe.

Calsamiglia, H., \& Tusón, A. (1999). Las cosas del decir: Manual de Análisis del Discurso. Barcelona: Ariel.

Fairclough, N. (2012). Political Discourse Analysis. London/New York: Routledge.

Hernández Sampieri, R. (1998). Metodología de la investigación. México: McGraw-Hill.

Lakoff, G., \& Jonhson, M. (2004). Metáforas de la Vida Cotidiana. Madrid: Ediciones Cátedra Grupo Anaya, S.A.

Márquez, S.L. (2012). Eufemismos en el discurso político. Recuperado de http://www.perfil.com/ ediciones/2012/6/edicion_688/contenidos/noticia_0092.html

MoustaouiSrhir, A. (2011). La construcción del sujeto y la auto-representación en los discursos de Muaamar Al Gaddafi: hacia la auto-deslegitimación. Discurso \& Sociedad, 5(2), 299-332.

Pardo, N. (2012). Discurso en la web: pobreza en YouTube. Bogotá: Grafiweb.

Pardo, N. (2013). Cómo hacer análisis crítico del discurso. Una perspectiva. Latinoamericana. Bogotá: Opr-digital.

Pardo, N. (2011). Aproximación al estado del arte de los estudios críticos del discurso en: aproximaciones interdisciplinares al estado de los estudios del discurso. (Juan Ruiz Comp.). Bogotá: UNC-IECO.

Pardo, N. (2009). Discurso público y la construcción de poder. Oralia, 12, 123-153.

Pardo, N. (2013). Violencia simbólica, discursos mediáticos y reproducción de exclusiones sociales. Discurso E Sociedad, 7(2), 416-440. 
Ricoeur, P. (2006). Teoría de la interpretación. Siglo XXI editores, s.a. de c.v.

Van Dijk T. (2000). El discurso como estructura y como proceso. Barcelona: Gedisa.

Van Dijk T. (2000). El discurso como interacción social. Barcelona: Gedisa.

Van Dijk T. (2009). La contextualización del discurso parlamentario. Barcelona: Gedisa.

Van Dijk T. (2011). Sociedad y discurso. Barcelona: Gedisa.

Sánchez García, F. J. (2009). Usos metafóricos del lenguaje político español. La metáfora estructural en los debates sobre el estado de la nación. Recuperado de http://www.um.es/ lacell/aelinco/contenido/pdf/67.pdf

Unda, V. (1998). El juego de los enunciadores en un discurso politico (discurso del Presidente del Colegio de Profesores de Chile, en la marcha nacional por la dignidad del magisterio, 16 de Octubre de 1998). Recuperado de http://www.lingref.com/cpp/wss/2/paper1142.pdf 